\title{
A República Lusitana das Letras: um retrato das redes de comunicação dos jornais emigrados no início do século XIX
}

\author{
The Lusitanian Republic of Letters: a portrait of communication networks of emigrant \\ newspapers in the early Nineteenth Century
}

\author{
Luís Francisco Munaro \\ Doutor em História pela \\ Universidade Federal Fluminense \\ luis.munaro@ufr.br
}

Resumo: O objetivo deste artigo é investigar as formas de idealização e construção da República das Letras entre os portugueses quando da sua dispersão a partir de 1808 e da tentativa de manter circuitos regulares de correspondência. Em outras palavras, através da publicação de grande número de jornais. Estes impressos têm lugar, sobretudo, em Londres, que sediou, entre 1808 e 1822, pelo menos oito jornais lusófonos a partir da iniciativa pioneira de Hipólito da Costa; e Paris, que sediou pelo menos três entre $1815 \mathrm{e}$ 1822, sobretudo em torno do intelecto de Solano Constâncio. A partir dessa rede de intercâmbio de ideias que começava a se expandir e adquirir um caráter cosmopolita, é possível indagar também sobre alguns dos diálogos mais amplos estabelecidos com publicações em língua inglesa e espanhola, de forma a permitir um vislumbre da dimensão dessas redes de comunicação cujas portas eram abertas pelo jornalismo.

Palavras-Chave: República das Letras, ilustração luso-brasileira, história do jornalismo.

\begin{abstract}
The purpose of this article is to investigate ways of idealization and construction of the Republic of Letters between the Portuguese when their dispersion from 1808 and their attempt to maintain regular circuits of correspondence. In other words, by publishing large number of newspapers. These papers take place, especially, in London, which hosted between 1808 and 1822, at least eight Portuguese-speaking newspapers from the pioneering initiative of Hipólito da Costa; and Paris, which hosted at least three between 1815 and 1822, especially around the intellect of Solano Constâncio. From this network for the exchange of ideas that began to expand and acquire a cosmopolitan character, it is possible also investigate some of the broader dialogues established with publications in English and Spanish, to allow a glimpse of the extent of these communication networks whose doors were opened by journalism.
\end{abstract}

Keywords: Republic of Letters, LusoBrazilian enlightenment, history of journalism. 
A República das Letras, noção que se difundiu entre intelectuais a partir do século XVI e obteve particular repercussão no século XVIII, não possuía um espaço físico ou institucional, apesar de encontrar especial difusão nas Academias de Ciências, Lojas Maçônicas e nos Salões. Também não havia leis que regessem o corpo da comunidade de letrados que buscavam intercambiar as suas ideias. Os cidadãos que formavam a república deveriam partilhar noções semelhantes relativamente ao progresso e harmonia, para além das fronteiras e vaidades nacionais - o que, evidentemente, nem sempre acontecia. Para tanto, julgavam-se suficientemente abertos para escrever e relatar as suas experiências, envolvendo-se ativamente com o mercado editorial, já que a tipografia era a forma mais eficaz de vencer as barreiras do espaço. Como lembra Ian McNelly, sobre o fenômeno da redação de cartas entre os ilustrados, ela apontava para civilidade, amizade, polidez, generosidade, benevolência e tolerância, características fundamentais para a produção e circulação do conhecimento (MCNELLY \& WOLVERTON, 2008: 130). O acúmulo de experiências, segundo esse raciocínio, deveria ser capaz de guiar o homem em direção a um conteúdo que pudesse abrigar a diversidade, tornando-se crescentemente universal.

Essa universalidade, contudo, se chocava com a forte inclinação nacional notada pela maior parte dos apóstolos do iluminismo. Além da busca por pensar a nação e celebrar os feitos nacionais, parecia subsistir uma inclinação em conter a entrada de indivíduos que não manifestassem as mesmas tendências liberais. A hierarquia dos cidadãos da República passava a indicar os méritos pessoais e o comprometimento do indivíduo com a busca pelo saber, para além das hierarquias e etiquetas que predominavam no universo cortesão. Desta forma, persistia a necessidade de se adornar com costumes liberais e ao mesmo tempo um vocabulário capaz de gerar um circuito exclusivo, chamado, muitas vezes, de pedantismo ou filosofismo.

A comunicação poderia ser considerada, nesse sentido, uma espécie de final em si mesmo, já que, através do maior fluxo de informações, seria possível vencer o obscurantismo dos governos de Antigo Regime e ajudar a conciliar o homem com a razão, para lembrar o postulado kantiano de "saída da condição de minoridade". Os autores e participantes da República estavam próximos dos instrumentos de troca e circulação de bens simbólicos. E é precisamente esse o indício mais importante de que o indivíduo era capaz de ingressar a República: sua capacidade de relacionamento com os outros, geralmente por intermédio do mercado editorial. O divulgador das artes e ciências deveria 
deter o know how sobre como publicar e manter relações próximas com livreiros. A relação se torna tão próxima que acaba confundindo o filósofo com o publisher, como lembra Margaret Jacob:

We have undergone a major reassessment of the role of the printing press in early modern European culture. Rather than being seen as a mere vehicle for the dissemination of new ideas, its practitioners and technology are now recognized as distinct forces for cultural change in themselves. Here that thesis receives re-enforcement and extension into the first decades of the eighteenth century. In this account of radical coteries in the Netherlands, with access to the presses and their own publishing firms, the distinction between philosophe and publisher, between the enlightened man and the printed word, is inevitably blurred if not obliterated. Not by any means were all publishers and journalists like the radical ones we shall encounter in these pages; most were businessmen, pure and simple (JACOB, 2006: 114).

Ainda sobre o ideal que regia a República, Fernando Egídio Reis assegura a indissociabilidade do conhecimento e da comunicação. Isto é, aquele não poderia ser pensado sem um esforço contínuo de intercâmbio e busca pelo melhoramento social. No seu estudo doutoral sobre as redes científicas construídas pelos portugueses no início do século XIX, o autor afirma que

A República caracterizava-se pela procura da verdade e da comunicação entre os seus membros, que se empenhavam na concretização de um ideal de saber multifacetado, que abrangia diversos domínios que hoje consideramos ciências distintas. Antecedendo a especialização científica, a 'República das Letras' implicava um compromisso com o conhecimento e com a sua comunicação. Foi neste contexto que os periódicos científicos assumiram um papel determinante, constituindo o suporte cada vez mais utilizado dessa comunicação, e sucedendo, em importância, à epistolografia. Comunicar e tornar público era uma vertente que a correspondência pessoal entre 'sábios' não permitia desenvolver em toda a sua dinâmica, mas que é desenvolvida pelos periódicos científicos e generalistas (REIS, 2007: 37, grifos nossos).

Os sábios deveriam assim comunicar. Sua sabedoria estava diretamente ligada à sua capacidade de tornar públicas suas ideias, submetendo-as à República e aos outros homens. A epístola pública substituiu a epístola privada: as grandes cartas escritas 
tornaram-se um acontecimento que dizia respeito a toda a comunidade. A regularidade destas epístolas, destinadas à comunidade científica, foram também as precursoras do jornalismo enquanto comunicação periódica de informações (HABERMAS, 2003). Os jornais portugueses publicados em Londres e em Paris no início do século XIX, sobretudo os Annaes encabeçados pelo diplomata Solano Constâncio, já se situam nesse espaço de troca: pretendem mostrar ao mundo os talentos intelectuais dos portugueses. O jornal, assim, assumiu a função de comunicação regular do homem de letras. Ele demonstrava a preocupação contínua em fornecer ao leitor as expressões mais sofisticadas da literatura nacional (FERENCZI, 1993: 24).

Uma sólida comunidade de portugueses debutou nesse universo de letrados a partir de 1808, quando a instabilidade na península favoreceu um ciclo contínuo de migrações. Os principais destinos destes emigrados eram o Brasil, França e Inglaterra. Nesta última, pela liberdade e proteção garantida aos impressores através da legislação, os portugueses tiveram a oportunidade de se relacionar mais firmemente com o mercado livreiro, ingressando formas mais sofisticadas de pensamento ilustrado. Se, até então, os limites desse pensamento eram severamente circunscritos pela censura, a invasão napoleônica tornou esses mecanismos praticamente inexistentes, impulsionando um forte surto de impressos. Sobretudo em Londres, o contato próximo de livreiros permitiu a disseminação de grande variedade de escritos que julgavam estar vinculados ao pensamento das Luzes.

Entre os portugueses em Londres, o contato com o mercado livreiro costumava ficar nas proximidades da região de Fleet Street, que sediava grande número de impressores, ou do bairro Belgravia, onde estava localizada a Embaixada Portuguesa (Tabela 1). No caso da primeira publicação periódica em língua portuguesa de vulto naquela cidade, o Correio Braziliense, seu autor Hipólito da Costa chegou a custear a própria tipografia para facilitar a composição dos tipos e apressar a publicação e circulação de papeis. Nesse sentido, deter ou ser próximo dos instrumentos de produção era fundamental para o ingresso na República. 
Tabela 1- Impressores utilizados pelos portugueses em Londres

\begin{tabular}{|c|c|c|c|c|}
\hline Nome do Impresso & Ano & Impressor & Local & Referência \\
\hline $\begin{array}{l}\text { A Arte Poética de } \\
\text { Horacio, por Leonor } \\
\text { Almeida }\end{array}$ & 1812 & T. Harper & Fleet Street & \\
\hline $\begin{array}{l}\text { Cartas de Antonio } \\
\text { Martins Pedra }\end{array}$ & 1822 & E. Justin & Bricklane & Bairro Belgravia \\
\hline Correio Braziliense & $1808-1822$ & W. Lewis & Wych Street & $\begin{array}{l}\text { Acima da Ludgate } \\
\text { Street, que é sequência } \\
\text { da Fleet Street }\end{array}$ \\
\hline $\begin{array}{l}\text { Cartas de Heliodoro } \\
\text { Carneiro }\end{array}$ & 1821 & Cox and Baylis & $\begin{array}{ll}\text { Great } & \text { Queen } \\
\text { Street } & \\
\end{array}$ & Bairro Belgravia \\
\hline $\begin{array}{l}\text { Microscópio de } \\
\text { Verdades }\end{array}$ & 1815 & W. Lewis & Wych Street & $\begin{array}{l}\text { Acima da Ludgate } \\
\text { Street, que é sequência } \\
\text { da Fleet Street }\end{array}$ \\
\hline O Cатреа̃o & $1819-1821$ & L. Thompson & Great St. Helens & $\begin{array}{l}12 \text { quadras da Grub } \\
\text { Street, acima da Fleet }\end{array}$ \\
\hline O Espelho & $1813-1814$ & Mr. Hughes & Ludgate Street, 35 & $\begin{array}{l}\text { Sequência da Fleet } \\
\text { Street }\end{array}$ \\
\hline O Investigador & 1811-1819 & T. C. Hansard & Paternoster Row & $\begin{array}{l}\text { Uma quadra acima da } \\
\text { Ludgate, sequência da } \\
\text { Fleet }\end{array}$ \\
\hline O Português & $1814-1822$ & W. Lewis & Wych Street & $\begin{array}{l}\text { Acima da Ludgate } \\
\text { Street, sequência da } \\
\text { Fleet }\end{array}$ \\
\hline Padre Amaro & $1820-1828$ & Mr. Handsword & $\begin{array}{l}\text { Great Winchester } \\
\text { Street, } 21\end{array}$ & \\
\hline
\end{tabular}

Fonte: Autoria própria.

A partir dessa constatação sobre a importância do imaginário da troca e da partilha entre os herdeiros diretos do Iluminismo, o objetivo deste artigo é investigar as formas de apropriação e disseminação de discursos de que se utilizaram os portugueses, sobretudo quando da sua dispersão a partir de 1808 e da busca por conter a expansão napoleônica na península, mantendo circuitos regulares de correspondência: em outras palavras, publicando grande número de jornais. Estes impressos têm lugar, sobretudo, em Londres, que sediou, entre 1808 e 1822, pelo menos oito jornais a partir da ação pioneira de Hipólito da Costa, e Paris, que sediou pelo menos três, sobretudo em torno do intelecto de Solano Constâncio. A partir dessa rede de intercâmbio de ideias que começa a se expandir será possível indagar também sobre alguns dos contatos mais amplos estabelecidos com publicações em língua inglesa e espanhola. A amplitude desse processo de troca e partilha, que vai muito além da censura, permite perceber a contribuição do jornalismo para a manutenção de circuitos regulares de troca de ideias ilustradas. 


\section{Fluxo epistolar entre os portugueses}

Estudar os fluxos epistolares entre os portugueses implica levar em conta as mudanças precipitadas pela migração da Corte. A correspondência jornalística, tanto em Londres quanto em Paris, servia para restabelecer a conexão entre a Corte itinerante e aqueles que tinham permanecido na Europa. Ao escrever e compartilhar a sua insegurança com relação à "calamidade generalizada" em Portugal, os exilados buscavam restabelecer vínculos perdidos com a emigração e aprofundar a reflexão sobre estratégias para escapar da crise social, política e econômica. A conexão entre esses indivíduos exilados, estivessem eles em Londres, Paris, Lisboa ou Rio de Janeiro, eram essas mesmas trocas de cartas (DIOGO, CARNEIRO e SIMÕES, 2000; DOMINGUES, 2001). Se considerarmos o jornalismo uma espécie de epístola dirigida ao público, de forma regular, torna-se nítida a sua importância enquanto sustentáculo de vínculos políticos entre os elementos portugueses diaspóricos. Tanto a comunidade de leitores quanto os redatores de jornais esperavam que os funcionários públicos lessem e se instruíssem sobre os problemas do reino através da leitura. Mais do que isso, contudo, a epístola era dirigida ao rei: os jornais continham as preocupações dos povos traduzidas pelas reflexões dos homens mais ilustres. Não é demais lembrar a constante preocupação dos jornalistas com a compreensão do rei e com o bloqueio da leitura provocado pela censura ou pela má interpretação dos ministros (NEVES, 2003). Numa informação que cabe a Oliveira Lima, o próprio D. João VI lia cuidadosamente o jornal de Hipólito da Costa (LIMA, 1945: 18).

A tentativa de forjar, no ainda árido Portugal, uma rede de comunicações científica remete aos viajantes do século XVIII vinculados à Academia de Ciências de Lisboa. Foram eles que estabeleceram uma rede de trocas baseadas em epístolas vinculadas ao pragmatismo pombalino e à busca pelo conhecimento, tentando estruturar, durante o percurso, um conjunto de conhecimentos capazes de amadurecer a economia do Reino português. Como lembra, sobre esse processo, Ângela Domingues,

de todos os pontos do Império, indivíduos de várias proveniências, com diferente formação, exercendo as mais diversas funções e dotados de objetivos diferentes enviavam aos órgãos da administração central sediada em Lisboa informações sobre os mais variados assuntos. Contudo, esses dados deviam contribuir para o conhecimento global do território (DOMINGUES, 2001). 
A rede de comunicação desses estrangeirados envolvia intelectuais que participavam dos mais variados campos disciplinares, sempre buscando a "modernização" portuguesa (DIOGO, 2000: 593). O anseio de se ver vinculado a esse circuito é explicitamente definido pelos redatores de periódicos no início do século XIX. O jornal de curta duração Microscópio de Verdades, publicado em Londres, menciona em 1814, nas suas páginas inaugurais, que "foi o amor, o zelo do bem, e da glória do meu Príncipe, e da minha Nação, o único estímulo que me moveu a entrar como escritor na República das Letras". De uma forma geral, os contatos entre os portugueses emigrados, a partir de 1808, seguem o mesmo padrão de comunicação dos estrangeirados do final do século XVIII, agora, contudo, com mais ênfase no material jornalístico, numa crítica mais abrangente acerca da política e também na metalinguagem como desdobramento natural da liberdade de escrever.

A rede estabelecida pelos editores e intelectuais portugueses, evidentemente, transcende o insulamento da comunidade portuguesa e mantém ativa interconexão com personalidades do mundo inglês e francês. Fernando Egídio Reis, em seu exaustivo catálogo sobre o interesse científico dos jornalistas portugueses, refere essas amplas redes abertas no estrangeiro:

O posicionamento dos editores portugueses é duplo: por um lado, encontramse próximos das principais instituições científicas da época e de alguns dos principais homens de ciência. Em alguns casos, contatam diretamente com personalidades relevantes do mundo das ciências, integrando assim redes de produção e circulação de conhecimento, e assistem a sessões públicas em instituições internacionalmente reconhecidas. Por outro lado, enquanto portugueses emigrados, conhecem o país de onde saíram, as suas carências, as suas instituições, as suas idiossincrasias. Neste sentido, pode afirmar-se que são representantes da periferia no centro, ao mesmo tempo em que representam o centro na periferia, tentando, não só informar o seu país das novidades e desenvolvimentos verificados no centro, mas também englobar o seu país nesse mesmo centro, através da exortação à produção científica (REIS, 2007: 26).

Os emigrados conheciam assim os obstáculos à difusão das ciências num Portugal onde ainda vigia a censura, inclusive aquela da Inquisição. Os jornalistas responsáveis por jornais tão variados como Correio Braziliense, O Investigador, O Português, $O$ 
Campeão e $O$ Padre Amaro continuamente rebatiam jornais estrangeiros reivindicando a autenticidade das produções portuguesas, sua legitimidade para figurar no circuito da República das Letras. Se, por um lado, os portugueses reconheciam sua situação periférica, por outro lamentavam que as produções da periferia não fossem devidamente consideradas pelos grandes periódicos de circulação internacional. Eis como preconizava o jornalista José Liberato no Investigador, publicado entre 1811 e 1819, em Londres:

É com efeito com grande mágoa que vemos que nem sequer uma página se dedica nesta exposição aos progressos feitos pelas Ciências no nosso Portugal. Parece que neste sentido o nosso país nem sequer é europeu; pois que nem sequer o seu nome se aponta, quando ao mesmo tempo se menciona um Reino tão pequeno e limitado como a Suécia. Será pois a razão deste esquecimento, porque não temos homens verdadeiramente sábios, e que possam honrar a sua Nação, como o fazem tantos outros dos diversos países da Europa? Nós não devemos fazer esta injúria à nossa Pátria quando sabemos, (e mesmo os conhecemos) que há homens eminentemente instruídos, que nos podiam acreditar, e fazer respeitados na República das Letras (Abril de 1814: 187, grifos nossos).

Os investigadores comentam a importância da interlocução entre os homens mais sábios, "homens de talento", para a conquista de um conhecimento mais elevado acerca do Reino Português. Quando, contudo, escritores como Solano Constâncio percebem que a ruptura operada pela razão na modernidade é muito brusca para ser encarada plenamente, seu instrumental começa a ser substituído pela "história enquanto mestra da vida" (RODRIGUES, 2011:7). De qualquer forma, a busca anunciada pela razão torna intensa e, em muitos casos, amigável a troca de memórias científicas. Os redatores dos Annaes, lembrando o caráter metalinguístico do seu jornal, comentam sua importância enquanto troca atual e regular de epístolas, cujo objetivo é:

promover a indagação e a discussão das matérias úteis, [para o que] nada pode concorrer tanto como os escritos periódicos; este meio é tão geralmente reconhecido eficaz, e o melhoramento sucessivo das Ciências, mormente das naturais, tem consagrado de tal modo a necessidade dele, que nenhuma nação civilizada pode hoje escusá-lo, sob pena de se ver em breve a um século de distância dos conhecimentos atuais; por ele se estabelece uma correspondência pronta e universal entre os homens sábios e industriosos, 
que muitas vezes, sem terem relações algumas pessoais, assim se conhecem, se estimam e se comunicam. Daqui vem que todos os países promovem e protegem continuamente novas publicações d'estes escritos (Annaes, Julho de 1818: 19-20, grifos nossos).

Surgia daí a necessidade de compartilhar a informação científica, como, nas palavras dos investigadores, um "grande benefício particular e público que daí pode provir" (Investigador, Maio de 1814, Apud. REIS, 2007: 176). O grande bem a que aludiam os escritores do Investigador era a nossa pátria. A razão, portanto, parecia ser de alguma forma refém das necessidades do Reino Português. Os republicanos não se cansavam de remeter o leitor para a árdua rotina de recolher informações e dispô-las, mantendo o caráter de atualidade, nos jornais. Esse imenso fluxo de informações alcançava os jornais através, muitas vezes, dos leitores irrequietos por ver suas preocupações expostas publicamente. Como argumentava Joaquim de Freitas no jornal $O$ Padre Amaro, publicado em Londres, o afluxo de cartas não permitia que o escritor tivesse tempo e nem competência para fazer uma seleção hábil:

[...] temos recebido uma grosa de cartas pelo two penny post. A maior parte delas é insignificante: algumas são cheias de expressões amigáveis e lisonjeiras; e quase todas exigem de nós uma franca e sincera explicação, sobre nossos verdadeiros sentimentos políticos. Bem puderam seus escritores ter evitado o trabalho de as escrever, lendo e refletindo nesse pouco que temos escrito; pois ali bem claramente se manifestam não só os princípios, mas também os meios e fins: confessamos que nos há de ser custoso explicá-los melhor, mas porque não digam que metemos a viola no saco, passamos a dar a explicação que nos pedem; advertindo que, sendo-nos impossível inserir todas as cartas por falta de espaço, só copiaremos uma (Padre Amaro, Outubro de 1820: 220).

Os jornalistas imprimiam, preferencialmente, os conteúdos que pudessem tanto ter uma importância imediata para o seu leitor quanto configurar um repositório importante para as "memórias do tempo". Sendo impossível, como lembrou Joaquim de Freitas, imprimir todo o material enviado pelos leitores. No caso de Londres, estes conteúdos eram dependentes do fluxo de malas postais e a proximidade da Fleet Street do porto no Rio Tâmisa favorecia a rápida circulação de conteúdos noticiosos. Os próprios jornalistas portugueses documentavam que as malas postais eram reviradas com 
avidez e logo dispostas na forma de um correio regular (NUNES e PEREIRA, 1993, p. 207). No caso em estudo, em que o jornalismo já se apresentava debaixo de pressupostos deontológicos rudimentares, sobretudo identificados com a ideia de periodicidade, atualidade e imparcialidade, a rede de comunicações ilustrada era estabelecida através de ampla convocação dos leitores para a participação, com contribuições escritas, fossem elas novidades, pensamentos, reflexões ou memórias.

Os periódicos não subsistiam sem a contribuição dos leitores, ainda que se vissem tentados a suprimir os conteúdos com os quais não concordassem, alegando que assim o faziam pelo "bem da pátria" (O Portuguez, V.I, 1814: 6). A atitude hospitaleira, comum aos homens de letras, era cobrada pelos próprios correspondentes, de forma que a publicação de cartas acabava indicando a liberalidade dos proprietários do jornal. Noutras palavras, se o jornal fosse suficientemente liberal e iluminado em seus propósitos, não podia se furtar a publicar uma comunicação importante. Em correspondência, um leitor do Campeão mencionava palavras do editorial do jornal para justificar a necessária publicação da sua carta:

Senhor Campeão Portuguez. Os amigos da Justiça e da Verdade viram o seu Prospecto em que diz, formais palavras: "Não estará também este Artigo (Correspondência) só aberto para certa classe de pessoas: os indivíduos de todas as opiniões poderão nele publicar seus escritos contanto que neles hajam as condições acima mencionadas (urbanidade e decência). Sem ampla e desapaixonada discussão não se chega ao templo da verdade": Neste caso está o escrito que lhe remetemos, e que também já foi publicado no Correio Braziliense. Se Vossa Mercê é sincero quando diz que é Amigo do Rei, deveo igualmente ser de seu filho o Príncipe Real: assim não recusará publicar a defesa dele, que com esta tem a honra de enviar-lhe (D.F.F., Apud Campeão, Agosto de 1819: 130).

A troca horizontal fazia parte da orientação da República e, enquanto isso, as memórias constantemente dirigidas ao rei isentavam o escritor de faltar com a verdade. Chamando a atenção do seu leitor para o monarca, ele utilizava um coringa contra quaisquer atitudes de censura e perseguição. Mais do que isso, dirigir comentários para o rei era visto como estratégia eficaz para, no ideário pragmático que orientava os jornais, consertar desvios na administração pública. Nesse sentido, o problema maior eram os ruídos na comunicação dos jornalistas com o seu rei, também causados pela ingerência 
dos ministros, no esquema mental chamado por Lúcia Maria Bastos Neves de “despotismo ministerial” (NEVES, 2003). Ao comentar as calúnias dirigidas contra o Conde de Palmela, Joaquim de Freitas também se referia a esse sistema de troca de epístolas com o rei:

Não há carta que se remeta ao rei por via destas criaturas (quer dizer, criaturas do rei, v. g. (sic) o Heliodoro, José Anselmo, e outros do mesmo jaez) que, ou não se abra ou se não suprima [...] Não há muito tempo que se praticou uma na Legação de Londres, que comprova bem isto; e é que havendo ordem na dita legação para se mandar ao Rei, sem interrupção, certos jornais; como dois ou três números dos ditos falavam sobre coisas pouco vantajosas ao Brazileiro estabelecido em Londres... (Apud Correio Braziliense, Outubro de 1820: 342$3)$.

É preciso lembrar que a remessa dos jornais para os subscritores era organizada pelos próprios editores. Com exceção dos Annaes, em Paris, os jornais emigrados optavam por manter na penumbra os nomes dos subscritores e os motivos para que isso fosse feito são óbvios. Os Annaes científicos, produzidos sob a liderança de Francisco Solano Constâncio entre 1818 e 1822, em Paris, publicaram em 1818 a lista de seus subscritores (QUEIRÓS, 1983: 27). Como o jornal não tinha pretensões políticoideológicas que podiam ser consideradas subversivas, seus leitores não corriam nenhum perigo. A lista dos subscritores dos Annaes oferece conclusões importantes no sentido de discernir o leitor real do virtual. Mesmo estando a redação no estrangeiro, a maioria dos leitores estava localizada em centros urbanos portugueses e brasileiros, sobretudo Lisboa e Rio de Janeiro. De um total de 748 leitores, 207 estão em Lisboa, 111 no Rio de Janeiro, 99 no Porto, 86 em Coimbra, 52 na Bahia e 47 em ilhas portuguesas (Ibid).

A quantidade de leitores situados em Portugal e no Brasil permite perceber o controle que o escritor possuía sobre a sua rede de distribuição de jornais. É notável como o Rio de Janeiro, onde, como sugere Marisa Lajolo e Regina Zilberman, a leitura era extremamente rarefeita (2002), consumia mais de 100 exemplares. Daí poder ser inferido o consumo relativamente alto que permitiu o surto de papeis impressos no Brasil a partir de 1821. De qualquer forma, ainda que o leitor esteja no Brasil, ele possui vínculos afetivos com Portugal. Os Annaes eram uma publicação portuguesa destinada a portugueses, ainda que debaixo do pressuposto de estar contribuindo para a construção da República das Letras (Ibid.) 
Ao contrário dos jornais mais voltados para o ensaísmo que foram responsáveis pelo princípio do jornalismo na Inglaterra, a exemplo do Spectator de Addison e Steele e do Weekly Review de Daniel Defoe - e mesmo do The Ghost, de Solano Constâncio - os jornais que compreendem a imprensa portuguesa emigrada não têm pretensões de direcionamento para o público feminino. Isso pode ser visto na limitação dos nomes de mulheres na lista de subscritores acima mencionada: foram encontradas apenas 3 , entre elas a Princesa Isabel e a Condessa de Oyenhausen. Também é notável o aparente desinteresse dos portugueses em Londres pelos Annaes. O único assinante ali é Antonio Machado Braga, amigo pessoal do jornalista José Liberato.

Outro fenômeno que merece ser apontado é a circulação de tópicos que permitem identificar um conteúdo semelhante e constituem pauta comum de discussões. Em alguns casos, é possível perceber como panfletos e livros eram lidos por toda a comunidade de jornalistas e ajudavam a aproximar um conjunto de indivíduos orientados por determinadas obrigações intelectuais. Noutras palavras, ainda que a opinião ou a informação fosse transmitida de uma ou outra forma, ela devia, necessariamente, ser transmitida. Isso pode ser visto especialmente durante o lançamento das Pièces Politiques na França, em 1820. Este opúsculo, que Joaquim de Freitas chama de Peça Impolítica, torna visível a grande quantidade de espaços que contribuíram para a formação da República Lusitana das Letras e a obrigação intelectual coletiva de tomar um posicionamento público diante de suas ideias consideradas "escandalosas". De fato, os jornalistas não hesitam em fazê-lo buscando, inclusive, afastar o risco de serem confundidos com o autor do opúsculo.

As pièces são um singelo escrito de 18 laudas em que se questiona a sucessão ao trono português pela Casa de Lafões e Cadaval, à qual se encontrava ligado o Marquês de Marialva. Segundo o escritor, a que responde formalmente o editor francês BousquetDeschamps, o Marquês é “intimement lié avec M. de F.*** l'un des secretaries de la régence de Portugal. On croit que ce dernier est ici le premier moteur du projet dont je vous parle, projet dont l'opinion et le bruit public paraissent appuyer la réussite" (BOUSQUET-DESCHAMPS, 1820: 18). O curioso a ser percebido é a amplitude da circulação e discussão pública do panfleto, que é comentado e criticado através de vários jornais, como se pode ver no seguinte excerto:

Um portuguez em Paris fez inserir nos jornais franceses uma carta refutando as aleivosas asserções do autor da Peça Impolítica, de que demos a tradução 
no número anterior. Esta carta é assinada - V.A.D.S. Não a copiamos por nos faltar espaço, assim como também outra inserida no Times, sem assinatura; mas que pelo estilo nos parece ser do Brazileiro estabelecido em Londres (Padre Amaro, Abril de 1820: 401).

Dessa forma, como alega Joaquim de Freitas, um "portuguez em Paris" Heliodoro Carneiro de Freitas, amigo pessoal de Hipólito da Costa - escreveu aos jornais franceses refutando o conteúdo das pièces, estas já traduzidas em português no Padre Amaro. Outras refutações ganharam espaço no Times, lembrando, segundo Freitas, a redação do Conde de Palmela - o "brazileiro estabelecido em Londres". Comentários ou ideias forjicadas num ou noutro ponto da rede ganhavam repercussão e eram rapidamente interpretadas pelos jornalistas - percebidos como formadores da "opinião pública". O próprio Conde de Palmela, pela frequência com que se manifestava em jornais londrinos, era chamado a tomar posicionamento diante desses eventos literários de importância coletiva.

A ampla rede montada entre os escritores, por um lado, tinha como subsídios a busca pela afirmação da condição de homem de letras e o alcance de um conhecimento mais profundo acerca da questão portuguesa e, por outro, a partilha de um arcabouço de práticas e argumentos que caracterizam as comunidades mais especificamente jornalísticas. Ainda que o jornalismo, nesse momento, estivesse muito vinculado ao beletrismo, suas configurações indiciam a comunicação regular e a ampla difusão de conhecimentos considerados atuais, que não necessariamente eram itens obrigatórios dentre as interlocuções dos homens de letras.

Além disso, sobravam as referências à venda de jornais parceiros, como no caso do Espelho, que propagandeava a venda do Correio Braziliense e da Narrativa da Perseguição, de Hipólito da Costa ( $O$ Espelho, maio de 1813: 8). Sua existência efêmera comprovou que não restava, ao redator Bernardo da Rocha Loureiro, disponibilidade de documentos que já não estivessem no Correio Braziliense, detentor de um círculo privilegiado de informantes, e do Investigador, detentor de mais recursos e capital humano. Talvez estes mesmos fatores tenham levado Rocha Loureiro a investir no caráter mais propriamente ideológico do seu jornal Portuguez, fundado em 1814, chamando atenção para a sua capacidade crítica e argumentativa. O redator, ainda no Espelho, assim elogiava os rivais: "O Investigador Portuguez em Londres há sido o teatro imparcial, onde se tem combatido as opiniões por e contra a Companhia [dos vinhos]; e do mês de 
Agosto que é o n. 26, extraímos este argumento que fazem as novas Companhias, copiado palavra por palavra de uma nota."(Ibid, Agosto de 1813: 139). A Gazeta de Lisboa também mencionou a venda do Investigador e (Gazeta de Lisboa, 31 de julho de 1815: 166), por outro lado, Liberato em seu Campeão se referia à infeliz Gazeta, ironizando sua falta de liberdade de escrita:

É fabricada na Secretaria dos negócios estrangeiros e o ministro desta repartição é quem simultaneamente lhe fornece os artigos, os ordena e censura. Julgai agora quão puro deve ser o ouro extraído dos cadinhos de um tal laboratório! Só um homem perverso seria capaz de suspeitar que pudesse haver liga em obra tão apurada: é ela por conseguinte o ouro mais puro que temos em Portugal (Carta de F.D.F., O Campeão, 1 de agosto de 1819: 97).

A entrada em cena, em 1820, de Joaquim Ferreira de Freitas, que até então foi apenas espectador do surto impresso no emigrado, alterou o nível de reflexividade e ajudou a aprofundar a inteligibilidade que a imprensa emigrada tinha dela própria e do seu papel político. $\mathrm{O}$ redator deu, num primeiro momento, indícios de respeitar tanto Hipólito da Costa quanto Rocha Loureiro. Assim que se avizinhou a Revolução Liberal do Porto, as relações entre os escritores ficaram mais tensas. Freitas logo discriminou o redator do Portuguez, dizendo que este mantinha uma rede espúria de contatos e, justamente por conta disso, era incapaz de fornecer informação de melhor qualidade. Para tanto, o redator do Padre Amaro mencionava a amplitude das comunicações da imprensa francesa, no sentido de se permitir um cálculo mais apurado da verdade, em comparação com o limitado jornal de seu rival. De quebra, mencionava as formas apenas incompletas de Rocha Loureiro pescar e comunicar informações:

O Portuguez cuida que os redatores na França passam o seu tempo em andar por dois outros escritórios pescando notícias oficiais, ou passeando em Tuillerias, como ele em Hyde Park para ver se algum passeante lhe fornece material a algum artigo ou pretexto a alguma calúnia. O círculo dos Redatores em França, qualquer que seja a cor do seu jornal, é muito mais extenso, e o seu comportamento mais nobre do que imagina o Portuguez (Padre Amaro, Julho de 1821: 44).

Segundo Freitas, o redator do Português não tinha muita vocação para a reportagem, preferindo permanecer no terreno dos ataques pessoais. A ironia de Freitas 
era destilada também contra José Agostinho de Macedo, de forma que o redator, em pouco tempo de ação, pretendeu concentrar em si o papel de mediador dessa extensa comunidade de letrados, atirando contra tudo e todos. Num momento em que se torna recorrente e mesmo necessário alardear posições políticas liberais, a moderação de Freitas era vista com desconfiança tanto por liberais quanto por absolutistas.

Assim que explodiu a Revolução Liberal do Porto, a necessidade de se comunicar e receber notícias de Portugal se tornou muito maior, e de igual modo a aspiração de interferir mais ativamente nos rumos políticos da península. Os debates que surgiam mobilizaram vasta rede que envolvia espanhóis interessados no destino constitucional de Portugal, exilados portugueses na França, os liberais britânicos e, evidentemente, os brasileiros. No cerne destes debates estava a temática constitucional, que exigia a manifestação pronta dos homens de letras.

Cumpre por fim dizer que, para jornais como O Campeão, O Portuguez e Correio Braziliense, a comunicação aparecia como uma ideologia: comunicar-se é manifestar proximidade do ideário liberal. Há que se mostrar publicamente, já que assim se constrói a política, ao invés dos Conciliábulos denunciados constantemente. Monta-se todo um circuito, que tem nos espaços de sociabilidade um ponto de partida e nos jornais um ponto de escape, de fortalecimento das maneiras liberais - considerando que liberalismo é também uma forma de se comportar. E, ressalta-se, a comunicação está no centro de tudo isso. Não comunicar, de quebra, é sujeitar-se aos princípios de segredo do antigo Estado absolutista. Assim, o sujeito liberal deve estar pronto tanto a frequentar os espaços da moda quanto a apresentar-se nos jornais.

\section{Diálogos internacionais}

Dentre os letrados portugueses do início do século XIX, muitas vezes a opção pela França ou pela Inglaterra revelava as próprias disposições ideológicas dos escritores. José Anselmo Correia Henriques é um caso exemplar disso: por manifestar opiniões absolutistas e antimaçônicas, foi isolado pela comunidade portuguesa em Londres e obrigado a retirar-se para a França em 1809. Em 1821, novamente na Inglaterra, ele pôs à prova uma nova tentativa de comentar os avanços das Cortes de Lisboa, não obtendo, mais uma vez, sucesso. O periódico Zurrague (1821), tanto quanto o Argus (1809), teve vida curta e o seu autor foi chamado pelas Cortes de Lisboa a prestar esclarecimentos 
sobre a expressão "corja de peralvilhos" (Padre Amaro, Setembro de 1821: 204). Novamente em Paris, em 1823, ele publicou suas odes contra o liberalismo, nas quais imprecava contra Bernardo da Rocha Loureiro, a voz liberal que persistia em Londres uma vez já finados o Campeão e o Correio. Sua opção pelo absolutismo fez com que tenha permanecido, durante a efetivação das ações da Santa Aliança, na França. Outro caso é o de Francisco Solano Constâncio que, desde muito cedo, tendo revelado tendências pró-bonapartistas, evadiu-se para a França onde se tornou panfletário da revolução. Nesse sentido, como afirma Fernando Egídio Reis, "mesmo após a revolução liberal portuguesa, as divergências políticas entre os que optaram por Londres ou por Paris para local de exílio continuavam a ser evidentes e a integrar o discurso ideológico e político" (REIS, 2007: 84).

Entre 1815 e 1820, os três periódicos portugueses publicados na França possuíam objetivos mais marcadamente científicos, sem deixar, mais com o intuito de combater a influência de Hipólito da Costa e derivados, de tocar nos temas políticos. Eram eles $O s$ Annaes, O Observador Lusitano e O Contemporâneo. Francisco Solano Constâncio deu início à imprensa lusa em Paris com o Observador Lusitano em Paris, que circulou no primeiro semestre de 1815. Segundo Constâncio, esta publicação tinha como objetivo justamente contrabalançar a influência exercida pela imprensa londrina:

Eu bem quisera não me meter com a política e limitar-me às matérias literárias e científicas, porém o público está há anos acostumado a governar o mundo em seco, e os mais ignorantes discorrem sobre a política como se a entendessem, deixando com tédio os artigos um pouco profundos das artes e ciências, de cujo merecimento não são contrastes (sic). Se S. A. R. e V. Ex. ${ }^{a}$ se dignassem proteger a minha empresa estou certo de a tornar executar em um plano mui superior ao dos jornais portugueses de Londres (Apud. REIS, 2007: 235, grifos nossos).

Constâncio não apreciava muito Hipólito da Costa, como registra em suas correspondências. Contudo, em seus contatos reservados através de cartas, é sempre mais incisivo e cáustico do que nos seus impressos públicos, nos quais adota um tom de respeito e moderação. Em 1822, Constâncio registrava numa carta a Silvestre Pinheiro Ferreira: 
Seria bem conveniente e mui acertado tirar daqui [Londres] Hippolyto, que é intrigante da primeira ordem, e que está instigado pelo gabinete inglês e creio que pelo Marechal Felisberto Caldeira a escrever de maneira a excitar os brasileiros a desunirem-se de Portugal. Ele é mui amigo de dinheiro e venal por caráter e hábito, e será fácil comprar o seu silêncio com dinheiro ou com algum emprego de natureza a não poder ele ser nocivo. Lembra-me que a missão de Haiti ou outra semelhante conviria bem, para o tirar de Londres, acompanhando-se a nomeação de uns tantos cartuchos (Apud. SOUSA, 1988: 95).

Dessa rixa entre o mais importante intelectual luso-brasileiro na Inglaterra e o mais expressivo intelectual português na França, pode-se obter alguma dimensão do estado de rivalidade em que viviam os jornais produzidos a partir de ambas as comunidades. Os egos dos jornalistas combatiam por uma informação de qualidade superior mas, sobretudo, pela posse de projetos mais concordes com o desejo do povo português - ou de suas fontes de financiamento. Os jornais portugueses na França evitavam se pronunciar abertamente sobre temas políticos, limitando-se a tentar responder às investidas liberais da imprensa em Londres. Formado médico em Edimburgo, Constâncio migrou para a França em virtude de sua simpatia pela Revolução Francesa e foi interlocutor ativo de Hipólito da Costa, sobretudo a partir de 1820 (REIS, 2007: 495). Seu percurso é bastante singular: mais do que Hipólito da Costa, Constâncio estabeleceu embaixadas entre hispano-americanos em Londres, auxiliando no avanço do ideário independentista. Contudo, ao contrário de Hipólito, Constâncio só via sentido nas independências das colônias hispânicas, pregando a subserviência do Brasil a Portugal no antigo formato colonial (Ibid).

O diálogo dos portugueses com a comunidade de revolucionários hispânicos não é suficientemente documentada pelos trabalhos historiográficos, nem tampouco mencionada nos jornais da época. Sabe-se, contudo, que havia um tecido discursivo de temas e argumentos compartilhados, relativos ao estado natural das colônias hispanoamericanas, muito na esteira do que pensou o abbé Raynal (RAYNAL, 1993). A lógica da argumentação republicana, contraditoriamente, se ancorava na figura do rei: repúblicas eram o desdobramento natural de governos deixados órfãos. O reino postiço de Fernando VII, na Espanha, autorizava a formação de repúblicas na América espanhola. O mesmo não acontecia no Brasil. Se considerarmos a eficácia e longevidade da Gran Logia Reunión Americana (ROMERO et all, s/d), que apostolava ideias muito próximas das de 
Constâncio, poderemos sugerir até mesmo algum grau de participação de ambos num ideário comum.

A publicação do Observador Lusitano (1815) se deu logo após o início da redação de Liberato no Investigador (1814), de Loureiro no Português (1814) e de Alpoim no Microscópio (1814). O impulso coletivo em Londres parece ter alimentado a palavra impressa portuguesa também em Paris. Eram os ecos da reorganização do mapa europeu após a derrocada de Napoleão e marcaram a grande ansiedade que antecedeu o Congresso de Viena. No caso de Constâncio, resguardado pela ideia da imparcialidade científica, ele também se propôs a conter a influência crescente dos portugueses em Londres. Sua estreia no mundo jornalístico, contudo, remetia a 1797, quando fundou o periódico The Ghost, ainda na Escócia. Trata-se do mais longevo jornalista português e sua experiência ajuda a documentar e dar uma dimensão mais precisa da dificuldade da manutenção de uma publicação periódica no início do século XIX. Constâncio lembra que em Paris apenas 100 exemplares vendidos por mês eram suficientes para custear sua atividade jornalística (REIS, 2007:235). É sabido que os custos - tanto de vida quanto relativo ao papel impresso - em Paris eram menores. Ao mesmo tempo, Constâncio revelava uma diferença substantiva em sua busca pelo mecenato: ainda que fazendo a defesa do trono e do rei, ele quer exprimir essa defesa pela mão amiga do Conde da Barca - aquele que, segundo Hipólito da Costa, encarnava valores negativos para o Reino Luso-brasileiro:

Segundo Constâncio [...] bastavam-lhe 100 assinantes para suprir as despesas de impressão, não havendo mais despesas senão o seu próprio trabalho, uma vez que garantiria sozinho a publicação do periódico. Para assegurar o sucesso deste projeto, pedia a proteção do Conde da Barca e do Rei. Em troca, prometia ser moderado e evitar as críticas aos assuntos e personalidades portugueses (Ibid).

Tanto Solano Constâncio quanto seus futuros parceiros no jornal Annaes das Sciencias, das Artes e das Letras - José Diogo Mascarenhas Neto, Candido José Xavier Dias da Silva e Luís da Silva Mouzinho de Albuquerque - mantiveram larga relação com personalidades da República das Letras à época, entre eles Adrien Balbi, que residiu em Lisboa em 1820. Aliás, bem pode ter sido este a escrever, em julho de 1821, para o Padre Amaro sob o codinome un français qui a résidé a Lisbonne, justificando as atitudes do Marquês de Marialva diante da Corte Francesa. A condição dos exilados facilitava a construção dessa rede internacional de solidariedades políticas. A impressão deixada é 
que o exílio torna o indivíduo suficientemente flexível para absorver ideias que seriam consideradas perjúrio em sua terra natal. Talvez em virtude da "calamidade generalizada" de Napoleão Bonaparte que levantou um estigma sobre a herança francesa, esses interlocutores francófonos pudessem estar mais diretamente impelidos a evitar a política e se refugiar na ciência, dando apenas retoques pontuais em doutrinas consideradas equivocadas. Indício disso é que todos os três periódicos portugueses surgidos na França serem marcadamente científicos.

Sobretudo pouco clara foi a trama que ligou os portugueses em Londres aos espanhóis e, mais especificamente, aos espanhóis estabelecidos em Londres. A sugestiva hipótese de Lúcia Maria Veloso (1987), de que os jornais portugueses bebiam grande influência do periódico do angloespanhol José Maria Blanco White, publicado ente 1810 e 1814, pode ter algum fundo de verdade. O jornal El Español foi criado com o mesmo objetivo do Correio Braziliense de instruir os compatriotas acerca das importantes mudanças em curso na Europa. Sua edição inicial abrigava os mesmos postulados patrióticos. Ele avançou as discussões sobre a temática constitucional na Espanha, que, afinal de contas, aprovou sua primeira Constituição em 1812. A leitura do jornal El Español, contudo, não revelou nenhuma interlocução mais direta com os portugueses. Por outro lado, White se apresentou em reunião na taverna frequentada pelos portugueses, a City of London, em 1810, quando D. Domingos de Sousa Coutinho ainda era membro de honra. Na ocasião, ele foi citado pelo Investigador como um importante colaborador inglês. White foi ainda citado por outro periodista espanhol, Alcalá Galiano, como sendo um membro ilustre da República das Letras espanhola, tendo frequentado, antes de se evadir para Londres, as sociedades literárias de Madri - as mesmas, aliás, que Rocha Loureiro. Já em Londres, seus comentários sobre as formas de organização das Cortes de Cádiz ganharam ampla repercussão (ALCALÁ-GALIANO, s/d: 68 e 127).

O periódico El Español Constitucional, surgido em Londres em 1819 sob a direção de Fernandez Sardinó, parece ter tido, este sim, uma influência maior sobre os portugueses - mas, por outro lado, era ainda mais por eles influenciado. Em carta de abril de 1819, um correspondente observava:

No puedo expresar á ustedes con qué jubilo hemos aplaudido en esta capital innumerables patriotas el proyecto de establecer en Londres un Periódico Español Semanal, para vindicar el honor de la Nacion Española, y de sus augustas Cortes, deshechas por medio del ataque mas brusco y bárbaro, que 
ofrecen los Anales de la historia antigua y moderna (El Español Constitucional, Abril de 1819: 24, no original).

Como revelava o correspondente, a empreitada era levada a cabo por vários espanhóis estabelecidos em Londres (Ibid: 204). Conforme, contudo, avançavam as críticas ao jornal, alguns dos colaboradores, sentindo-se amedrontados, escreveram para Sardinó buscando livrar os seus nomes de possíveis perseguições (Ibid: 227). É possível perceber que, em Londres, essa incipiente imprensa hispânica possuía maturidade menor que a imprensa portuguesa, no seio da qual os redatores estavam suficientemente treinados para afastar ou divulgar rumores e responder ataques da burocracia portuguesa. $\mathrm{Ou}$, mais provavelmente, o aparelho repressivo espanhol era muito maior e mais amedrontador. De qualquer forma, ao que tudo indica, a empreitada de quatorze anos, solidificada através do esforço pioneiro de Hipólito da Costa, alcançou um grau razoável de solidez. A experiência internacional de Hipólito, que percorria desde a formação dos periódicos republicanos nos Estados Unidos até o surgimento da imprensa diária em Londres, serviu de tutora para a experiência portuguesa emigrada.

Revelando a influência que sofria da imprensa portuguesa, Sardinó noticiou a produção do Portuguez, que demonstraria a "ilustração" e o "amor à liberdade" no seio do pequeno reino português. Ao mesmo tempo, Loureiro foi aquele entre os portugueses que mais se aproximou do ideário da união ibérica, daí estar mais próximo dos espanhóis:

Cuantas veces en medio de mis mas leales amigos he dicho com dolor: "hasta los portugueses tienen en Londres un periódico, titulado El Portugués, que honra á esa pequeña Nacion, que difunde en ella la ilustracion y el amor á La libertad; y la vasta Nacion Española no tiene siquiera un Periódico, que sirva de freno al Despotismo, que La está exterminando cada vez con mas furor!” (Ibid: 25, no original).

Dessa proximidade dos espanhóis em Londres com Rocha Loureiro, supõe-se os ataques que, segundo Freitas, El Español Constitucional viria a lhe fazer adiante. Sardinó condenou constantemente a redação de Freitas, considerado pelos portugueses um corcunda, e também Hipólito da Costa, considerado um absolutista abrasileirado. A pena mais incendiariamente liberal de Rocha Loureiro, contudo, rendeu-lhe os elogios do Español Constitucional. 
A discussão mais acalorada com um periódico em língua espanhola ficou por conta do Correo del Orinoco, da Venezuela. Quando Hipólito diminuiu a dimensão da Revolução Pernambucana de 1817, para reforçar as suas alegações de que uma República não estava no itinerário dos povos brasileiros já que estes povos tinham um rei, o Correo del Orinoco teria entrado no Brasil divulgando várias doutrinas separatistas e republicanas. A longa troca de farpas é mais interessante pela natureza dos periódicos do que pelos argumentos em si mesmos: um órgão venezuelano que entrava no Brasil fazendo propaganda republicana e um órgão monarquista impresso em Londres que chegava ao Brasil clandestinamente ao mesmo tempo em que ao serviço do rei, condenando a tentativa pernambucana de república (TORRES-CENDALES, s/d). A conclusão de Hipólito foi a seguinte: "Isto pois serve de indubitável prova de [...] que o escritor, mui desingenuamente tomou o pretexto de refutar nossos escritos, e mesmo fazer-nos invectivas pessoais, meramente para ter ocasião de introduzir suas doutrinas e dirigi-las aos povos do Brasil" (Correio Braziliense, V.XXIII: 46). Evidentemente, não se pode descartar a hipótese de que o redator (ou os redatores) do Correo del Orinoco conhecerem pessoalmente Hipólito da Costa, quando das muitas comitivas de hispanoamericanos que se dirigiram para Londres buscando negociar o apoio da Inglaterra - e, dada a limitação numérica das esferas políticas e intelectuais, estes elementos não incomumente se conheciam. Disso se induz, por outro lado, que Hipólito da Costa não podia ter uma relação de maior afinidade com Miranda ou Bolívar, a quem se atribui a fundação do Correo del Orinoco (TORRES-CENDALES, s/d). No dissídio, El Español Constitucional de Sardinó tomou as dores do Correo, o que torna possível perceber que a temática constitucional aproximava os espanhóis liberais dos hispano-americanos republicanos:

Siendo repugnante á esta idea el error reproducido en el Correio Brasiliense, apelaron á la revelacion los déspotas coronados, y la fixaron en los delirios de la imaginacion para hacer pasar la doctrina escandalosa de este periódico: fué menester engañar á los pueblos con la invencion fabulosa del origen divino de los reyes: los sueños de la mitologia produxeron monarcas semi-dioses por la línea paterna; y he aquí abierto el camino para revestirlos de uma autoridad, independiente y agena del pueblo. Para afianzar la usurpacion de los derechos del hombre, se urdió la fábula del poder divino de los reyes. Engañadas las naciones con el artificio de sus sacerdotes, interesados en la patraña, llegaron á ser el juguete de los que usurpaban su soberania, hasta que la luz del 
desengaño, ó el exceso enormísimo de la tirania las estimulaban al sacudimiento del yugo, y á echar por tierra la pesada carga de sus opressores (El Español Constitucional, Junho de 1819: 111, no original).

E, por outro lado, as boas referências do Correo del Orinoco ao seu parceiro ideológico em Londres, El Español Constitucional, foram constantes (TORRESCENDALES, s/d). O estudo do Correo del Orinoco revela ainda o grau de aceitação que possuíam os jornais The Times e Morning Chronicle na América Latina. Boa parte das informações provenientes da Europa eram extraídas destes jornais, posto que considerados parceiros dos independentistas (Ibid). Trata-se de uma afinidade ideológica que se percebe desde os primeiros números de El Español, bastante próximo do Abbé Raynal no que concerne à reflexão sobre as colônias americanas.

\section{Considerações finais}

Teria sido impossível, no limite deste artigo, dar conta da amplitude do círculo discursivo que os portugueses construíram a partir da diáspora de 1808. O que coube demonstrar foi que essa ventilação intelectual, combinada com um vasto processo de reflexão sobre as raízes econômicas dos problemas do Reino Luso-brasileiro, está intimamente ligada à criação de canais jornalísticos capazes de manter uma circulação de ideias mensal, semanal ou, em último caso, diária.

Esse foi o primeiro passo para a criação de doutrinas editoriais, relacionamento mais íntimo com o mercado livreiro e também a construção de grupos de leitores assíduos versados em temas políticos importantes para a vida direta da comunidade política, fenômeno que também está subjacente à construção de uma classe média (O`BOYLE, 1968: 301). Não apenas os portugueses diasporizados encontraram amplo espaço para reflexão e intercâmbio de ideias como negociantes e comerciantes, também diasporizados, descobriram na atividade jornalística um importante instrumento de formação intelectual e representatividade pública.

A esfera pública então em processo de consolidação ultrapassa os limites de Portugal e invade o mundo luso-brasileiro no início do século XIX (RIBEIRO, 2004): negociantes e diplomatas preocupados diante da situação periclitante do Reino e da intrusão militar ou financeira de outros países, buscavam os jornais para elevar suas ideias à leitura pública, acionando a vasta comunidade política portuguesa para buscar fazer 
valer as suas prioridades políticas. Até pelo menos a Revolução Liberal do Porto essas vozes enxergavam no rei a força primeira capaz de restaurar o Reino Português, livrandoo das conspirações internas e externas.

$\mathrm{Na}$ medida em que essa discussão entre portugueses, cujo ponto de partida é a “calamidade generalizada" gerada pela expansão napoleônica na Europa, se torna mais ampla, acaba atraindo também ingleses, espanhois, hispano-americanos e um público novo: o brasileiro. Os vários indivíduos que se intitulam porta-vozes dessas comunidades políticas acabam montando uma esfera de interlocução que, apesar de marcadamente política e doutrinal, tinha uma preocupação explícita com a literatura, a ciência e a divulgação dos maiores intelectos contemporâneos, ainda que sejam, em boa parte das vezes, pescados entre os pares nacionais.

\section{Fontes}

ABADE RAYNAL [1993]. A Revolução na América. Rio de Janeiro: Arquivo Nacional. ALCALÁ-GALIANO, Antonio [s/d]. Memórias de D. Antonio Alcalá Galiano. Disponível em: <http://www.cervantesvirtual.com/obra/memorias-de-d-antonioalcala-galiano--0/>. Acesso em: 10 mar. 2017.

BOUSQUET- DESCHAMPS [1820]. Piéces Politiques. Paris: Correard.

CARVALHO, José Liberato Freire [1819-1821]. O Campeão portuguez ou amigo do rei e do povo. Londres.

CASTRO, Bernardo José de Abrantes, CUNHA, Vicente Pedro Nolasco, CASTRO, Miguel Caetano e CARVALHO, José Liberato Freire [1811-1919]. O Investigador Portuguez em Inglaterra ou Jornal Literário, Politico, etc. Londres.

COSTA, Hipólito José da [1808-1822]. Correio Braziliense ou Armazém Literário. Londres: W. Lewis.

FREITAS, Joaquim Ferreira [1820-1828]. O Padre Amaro ou Sovela Politica e Literaria. Londres.

LOUREIRO, Bernardo da Rocha [1813-1814]. O Espelho. Londres.

LOUREIRO, João Bernardo da Rocha [1814-1822]. O Portuguez ou Mercurio Politico, commercial e litterario. Londres.

SARDINO, Pedro Pascasio Fernández e ACEVEDO, Manuel María [1818-1820]. El Español Constitucional. Londres: E. Justin.

WHITE, José Maria Blanco White [1810-1814]. El Español. Londres.

\section{Referências Bibliográficas}

ALVES, José Augusto dos Santos (1988). Ideologia e política na imprensa do exílio. Lisboa: Instituto Nacional de Investigação Científica.

DIOGO, Maria Paula; CARNEIRO, Ana \& SIMÕES, Ana (2000). Enlightenment Science in Portugal: The Estrangeirados and their Communication Networks. Social Studies of Science, vol. 30, n. 4, pp. 591-619 
DOMINGUES, Ângela (2001). Para um melhor conhecimento dos domínios coloniais: a constituição de redes de informação no Império português em finais do Setecentos. História, Ciências, Saúde-Manguinhos, Rio de Janeiro. vol. 8, suppl., pp.823-838.

DOURADO, Mecenas (1957). Hipólito da Costa e o Correio Braziliense. Rio de Janeiro: Bibliex.

FERENCZI, Thomas (1993). L'invention du journalisme en France. Naissance de la presse moderne à la fin du XIX siècle. Paris: Plon.

HABERMAS, Jurgen (2003). Mudança estrutural da esfera pública: investigações quanto a uma categoria de sociedade burguesa. Rio de Janeiro: Tempo Brasileiro.

JACOB, Margaret (2006). The Radical Enlightenment. Pantheists, freemasons and Republicans. Lafayette: Cornerstone.

LAJOLO, Marisa e ZILBERMAN, Regina (2002). A leitura rarefeita. São Paulo: Ática.

LIMA, Oliveira (1945). D. João VI no Brasil. Rio de Janeiro: José Olympio.

LIMA, Péricles (2012). A corte no Brasil e os periódicos portugueses (1808-1821). Tese (Doutorado). Universidade Nova de Lisboa, Lisboa.

MCNEELY, Ian F. e WOLVERTON, Lisa [2008]. Reinventing Knowledge. From Alexandria to the Internet. New York: W.W. Norton.

NEVES, Lúcia Maria Bastos (1999). A "guerra de penas": os impressos políticos e a independência do Brasil. Tempo, Niterói, ago. 1999. Disponível em: <http://www.historia.uff.br/tempo/artigos_dossie/artg8-3.pdf >. Acesso em: 12 jun. 2018.

NEVES, Lúcia Maria Bastos (2003). Corcundas e constitucionais. Rio de Janeiro: Revan.

NUNES, Mária de Fátima e PEREIRA, Sara Azevedo (1993). O Espírito da Cádiz em O Investigador Português em Inglaterra. Revista Cultura - História e teoria das ideias. n. 7.

VARGUES, Isabel Nobre e TORGAL, Luís Reis (s/d). Da Revolução à contra-revolução: vintismo, cartismo, absolutismo. O exílio político. In: TORGAL, Luís (Org.). História de Portugal. O liberalismo. Lisboa: Estampa.

O'BOYLE, Leonore (1968). The image of the Journalist in France, Germany and England, 1815-1848, X, n 3. Comparative Studies on Society and History. Disponível em: <http://ijpc.org/uploads/files/JSTOR\%20Comparative\%20Studies\%20on $\% 20$ Society\%20and\%20history.pdf>. Acesso em: nov. 2013.

QUEIRÓS, Fortunato (1983). Annaes das Sciencias das Artes e das Letras. Porto: Universidade do Porto.

REIS, Fernando Egídio (2007). Os periódicos portugueses de emigração (1808-1822). As ciências e a transformação do país. Tese (Doutorado). Universidade Nova de Lisboa, Lisboa.

RIBEIRO, Lavina Madeira (2004). Imprensa e espaço público. A institucionalização do jornalismo no Brasil. Rio de Janeiro: E-papers.

RODRIGUES, Thamara (2011). A independência do Brasil e o discurso do atraso português em História do Brasil de Francisco Solano Constâncio. In: OLIVEIRA, Camila Aparecida Braga, MOLLO, Helena Miranda \& BUARQUE, Virgínia Albuquerque de Castro (orgs). Caderno de resumos \& Anais do $5^{\circ}$. Seminário Nacional de História da Historiografia: biografia \& história intelectual. Ouro Preto: EdUFOP.

ROMERO, Ricardo et al (2010). Ediciones Masónicas Argentina. Una investigación del Centro de Estudios para la Gran Reunión Americana. Disponível em <http://logra452.blogspot.com/2010/02/los-precursores-de-la-revolucion.html>. Acesso em: 10 março de 2017. 
SOUSA, Maria Leonor (1988). Um ano de diplomacia luso-americana. Francisco Solano Constâncio (1822-1823). Lisboa: Imprensa Nacional.

TENGARRINHA, José (1965). História da imprensa periódica portuguesa. Lisboa: Coleção Portugália.

TORRES-CENDALES, Leidy Jazmín (s/d). Correo del Orinoco. Prensa colombiana del siglo XIX. Disponível em: <http://www.banrepcultural.org/blaavirtual/historia/prensa-colombiana-del-sigloXIX/correo-del-orinoco>. Acesso em: março 2017.

VELOSO, Lúcia Maria Veloso e SOUSA, José Manuel Mota (1987). História da imprensa periódica portuguesa: subsídios para uma bibliografia." Disponível em: <https://archive.org/details/bub_gb_5kcSHXG3sVYC>. Acesso em: 1 maio 2018.

Artigo recebido em 18 abril de 2017.

Aprovado em 27 de novembro de 2017. 